\title{
Functional Relationships between Rad18 and WRNIP1 in Vertebrate Cells
}

\author{
Akari Yoshimura, ${ }^{a}$ Masayuki Seki,,${ }^{* a}$ Tomoko Hayashi, ${ }^{a}$ Yumiko Kusa, ${ }^{a}$ Shusuke TadA, ${ }^{a}$ \\ Yutaka IshII, ${ }^{b}$ and Takemi ENomoto ${ }^{a, c}$ \\ ${ }^{a}$ Molecular Cell Biology Laboratory, Graduate School of Pharmaceutical Sciences, Tohoku University; Sendai 980-8578, \\ Japan: ${ }^{b}$ Shujitsu University, School of Pharmacy; Nishigawara, Okayama 703-8516, Japan: and ${ }^{c}$ Tohoku University 21st \\ Century COE program "Comprehensive Research and Education Center for Planning of Drug development and Clinical \\ Evaluation”; Sendai 980-8578, Japan. Received July 13, 2006; accepted August 19, 2006
}

The WRNIP1 protein interacts with WRN, the product of the causative gene for Werner syndrome. Mutation of the Saccharomyces cerevisiae gene MGS1, the yeast counterpart of WRNIP1, confers synthetic lethality with mutation of $R A D 18$. To examine the functional relationship between WRNIP1 and Rad18 in higher eukaryotic cells, we generated $W R N I P 1^{-1-/-} / R A D 18^{-/-}$lines from chicken DT40 cells and compared them with single mutant cell lines. Unlike the corresponding yeast mutant, WRNIP1 $1^{-1-/} / R A D 18^{-/-}$cells are viable but grow more slowly than single mutants and wild type cells, and they show an additive or synergistic elevation in the frequency of sister chromatid exchanges. As reported, $W R N I P 1^{-1-1-}$ cells and $R A D 18^{-1-}$ cells are moderately and severely sensitive to camptothecin (CPT), respectively. Unexpectedly, the severe CPT sensitivity of $R A D 18^{-/-}$cells is slightly suppressed by disruption of the WRNIP1 gene.

Key words Rad18; WRN interacting protein 1 (WRNIP1); DT40; maintenance of genome stability 1 (Mgs1); RecQ; proliferating cell nuclear antigen (PCNA)

Werner syndrome (WS) is a rare autosomal recessive disorder characterized by premature aging associated with an early onset of age-related diseases, including arteriosclerosis, malignant neoplasms, melituria, and cataracts. ${ }^{1)}$ The gene responsible for WS encodes WRN, a member of the RecQ family of DNA helicases. ${ }^{2)}$ The protein possesses DNA helicase and exonuclease activities. ${ }^{3-6)}$ Accumulating evidence suggests that WRN has roles relevant to telomere function since it efficiently prevents telomere degradation and consequent genomic instability. ${ }^{7,8)}$ Other functions of WRN are not well understood, although additional roles in many aspects of cellular metabolism may be inferred by its physical interaction with proteins involved in DNA replication, repair, and recombination, including DNA polymerase $\delta .^{9)}$

To obtain further insights into the function of WRN, we searched for WRN-interacting proteins by a two-hybrid strategy and found a novel protein which we initially denoted WHIP (Werner helicase interacting protein) ${ }^{10)}$ but which is now called WRNIP1 according to the nomenclatural conventions of HUGO. Interaction between the two proteins was further confirmed by their co-immunoprecipitation from cell extracts.

The amino acid sequence of WRNIP1 is similar to that of replication factor $\mathrm{C}$ (RFC), and it also contains the Walker A and B motifs for ATP binding and/or ATPase activity. ${ }^{10)} \mathrm{A}$ homologue of WRNIP1, MGS1, has been identified in budding yeast. ${ }^{11)}$ Previous studies have shown that overproduction of Mgs1 is lethal in mutants defective in proteins related to DNA replication, such as DNA polymerase $\delta$, RFC, PCNA, and RPA. ${ }^{12,13)}$ Moreover, we showed that mutation of mgs 1 partially alleviates the growth defect of the pol31 mutant, which bears a mutation in the second subunit of DNA polymerase $\delta .^{13)}$ Consequently, we proposed that Mgs1 (yWRNIP1) interacts with the DNA synthesis machinery to modulate the function of DNA polymerase $\delta$ during replication or replication-associated repair. ${ }^{13)}$ Indeed, we demonstrated that human WRNIP1 interacts with three of the four subunits of human DNA polymerase $\delta$ and stimulates its ac- tivity ${ }^{14)}$

To investigate the function of WRNIP1 in higher eukaryotic cells, we previously generated WRNIP1 gene knockout cells from chicken DT40 cells. ${ }^{15)}$ Because the WRNIP1 gene resides on chromosome 2, which is trisomic in DT40 cells, all three alleles were disrupted by gene targeting. WRNIP1 $1^{-/-1-}$ cells showed a slight elevation of sister chromatid exchange (SCE) and moderate sensitivity to the anticancer drug camptothecin (CPT) ${ }^{15)}$ an inhibitor of DNA topoisomerase I (Top1), which forms a complex with DNA.

It has been reported that the mgsl (wrnipl) rad18 double mutation confers synthetic lethality in the budding yeast $\mathrm{Sac}$ charomyces cerevisiae. ${ }^{12)}$ The yeast $\operatorname{Rad} 18$ protein is known to function in post-replication repair pathways, including an error-free damage bypass pathway involving $\operatorname{Rad} 30(\operatorname{Pol} \eta)$ and an error-prone damage bypass pathway involving Rev3/7 $(\mathrm{Pol} \zeta) .{ }^{16-20)}$ The rad18 mutants of lower eukaryotic cells show hypersensitivity to DNA damaging agents such as ultraviolet (UV), methyl methanesulfonate (MMS), and mytomycin C (MMC). ${ }^{21-23)}$ In the case of higher eukaryotic cells,

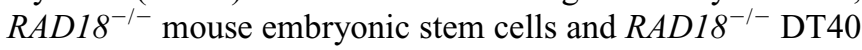
cells also show hypersensitivity to various DNA damaging agents such as UV and MMS. Moreover, both spontaneous and DNA damage-induced sister chromatid exchange (SCE) are elevated in $R A D 18$ knockout vertebrate cells. ${ }^{24,25)}$ Interestingly, $R A D 18^{-1-}$ DT40 cells were found to be hypersensitive to CPT, while $R A D 30^{-1-}$ and $R E V 3^{-/-}$cells, which are defective in $\operatorname{Pol} \eta$ and Pol $\zeta$, respectively, are as sensitive to CPT as wild type cells. ${ }^{26)}$ These data suggest a previously unanticipated role for vertebrate $\operatorname{Rad} 18$ in the processing of replication forks that encounter lesions induced by CPT. These circumstances prompted us to examine whether WRNIPI/RAD18 double gene knockout cells exhibit synthetic lethality, as observed for budding yeast, or if they are viable, whether they show a synergistically higher sensitivity to CPT.

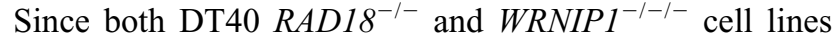
have been generated, ${ }^{15,25)}$ we constructed $W R N I P 1^{-1-1-}$ 
$R A D 18^{-1-}$ DT40 cells by transfecting two RAD18 targeting vectors sequentially into $W R N I P^{-1-/-}$ cells. We characterized growth, frequency of SCE, and sensitivity to DNA damaging agents including CPT in $W R N I P 1^{-1-/-}$ / $R A D 18^{-1-}$ cells and obtained unexpected results, as compared to data previously reported for budding yeast. We discuss functional relationships between WRNIP1 and Rad18 in higher eukaryotic cells.

\section{MATERIALS AND METHODS}

Cell Culture and DNA Transfection DT40 cells were cultured in RPMI 1640 supplemented with $100 \mu \mathrm{g} / \mathrm{ml}$ kanamycin, $10 \%$ fetal bovine serum, and 1\% chicken serum at $39.5^{\circ} \mathrm{C}$. For gene targeting, $10^{7}$ cells were electroporated with $30 \mu \mathrm{g}$ of linearized RAD18 gene targeting constructs ${ }^{25}$ ) using a Gene Pulser apparatus (BioRad, Hercules, CA, U.S.A.) at $550 \mathrm{~V}$ and $25 \mu \mathrm{F}$. Drug-resistant colonies were selected in 96-well plates with medium containing $0.5 \mu \mathrm{g} / \mathrm{ml}$ Puromycin or $20 \mu \mathrm{g} / \mathrm{ml}$ Mycophenolic acid. Gene disruption was confirmed by Southern and Northern blot analyses and RT-PCR. ${ }^{15,25)}$

Growth Curves Cells $\left(2 \times 10^{4}\right)$ were inoculated and cultured at $39.5^{\circ} \mathrm{C}$ for the specified periods. To maintain exponential cell growth, $3 \mathrm{ml}$ cultures were started in $30 \mathrm{~mm}$ diameter dishes, from which all cells were successively transferred into 60 and $100 \mathrm{~mm}$ dishes. The cells were counted and growth rates were estimated.

Measurements of MMS, CDDP, and CPT Sensitivity Cells $\left(3 \times 10^{2}\right)$ were plated into dishes containing various concentrations of methyl methanesulfonate (MMS), cisplatin (CDDP) or CPT in D-MEM/F-12 medium supplemented with $1.5 \%(\mathrm{w} / \mathrm{v})$ methylcellulose, $1.5 \%$ chicken serum, and $15 \%$ fetal bovine serum. Visible colonies were counted after 7 to $10 \mathrm{~d}$, and sensitivity to the treated reagent was represented as the percentage of cells forming colonies relative to that of untreated cells.

Measurements of Spontaneous and CPT-Induced SCE Frequencies Cells $\left(5 \times 10^{5}\right)$ were treated with $5 \mathrm{~nm} \mathrm{CPT} \mathrm{for}$ the last $8 \mathrm{~h}$ of incubation with $10 \mu \mathrm{M}$ BrdU for $16 \mathrm{~h}$. The cells were also treated with $0.1 \mu \mathrm{g} / \mathrm{ml}$ colcemid for the final $3 \mathrm{~h}$ of incubation to increase the proportion of mitotic cells. The cells were harvested and treated with $75 \mathrm{~mm} \mathrm{KCl}$ for $20 \mathrm{~min}$ at room temperature and then fixed with methanol-acetic acid (3:1) for $30 \mathrm{~min}$. The cell suspension was dropped onto ice-cold wet glass slides and air-dried. The cells on the slides were incubated with $10 \mu \mathrm{g} / \mathrm{ml}$ Hoechst 33258 in phosphate buffer ( $\mathrm{pH} \mathrm{6.8)} \mathrm{for} 20 \mathrm{~min}$ and rinsed with Macllvaine solution (164 mm $\mathrm{Na}_{2} \mathrm{HPO}_{4}, 16 \mathrm{~mm}$ citric acid, $\mathrm{pH}$ 7.0). The cells were exposed to a black light $(352 \mathrm{~nm})$ at a distance of $1 \mathrm{~cm}$ for $30 \mathrm{~min}$, incubated in $2 \times \mathrm{SSC}(0.3 \mathrm{M} \mathrm{NaCl}, 0.03 \mathrm{M}$ sodium citrate) at $62{ }^{\circ} \mathrm{C}$ for $30 \mathrm{~min}$ and stained with $3 \%$ Giemsa for $10 \mathrm{~min}$.

\section{RESULTS AND DISCUSSION}

Generation of WRNIP1 $1^{-1-/-} / R A D 18^{-/-}$DT40 Cells The observation that the wrnipl $(m g s 1)$ rad18 double mutant of budding yeast exhibits synthetic lethality ${ }^{12}$ prompted us to examine whether mutation of the WRNIPl gene affects higher eukaryotic cells with the $R A D 18^{-/-}$genotype.

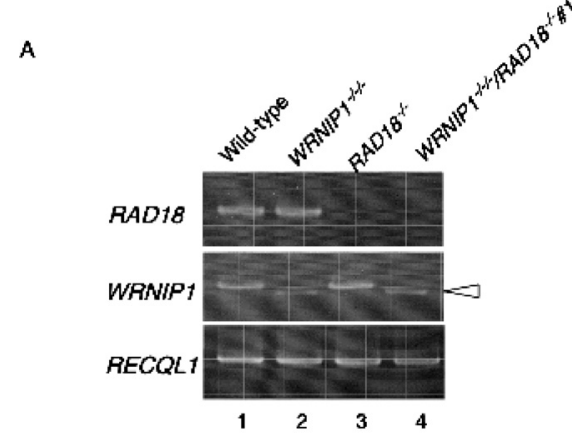

B

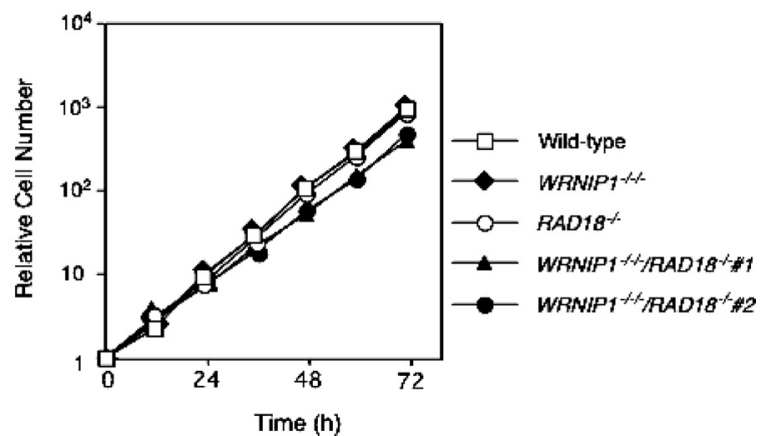

Fig. 1. Generation of $W R N I P 1^{-/-1-} / R A D 18^{-/-}$DT40 Cells

(A) RT-PCR analysis of total RNA from wild-type (lane 1), WRNIPI ${ }^{-1-/-}$ (lane 2),

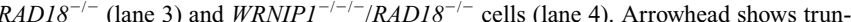
cated form of WRNIP1 expressed in WRNIPI ${ }^{-/-1-}$ cells. ${ }^{15)}$ (B) Growth curves of wild-

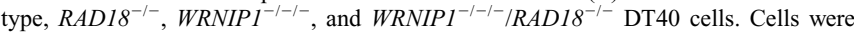
inoculated into $30 \mathrm{~mm}$ dishes and counted after the indicated periods. Cells that were negative for trypan blue staining were counted as viable cells.

Since we had $R A D 18^{-/-}$and $W R N I P 1^{-1-/-}$ cells derived from chicken DT40 cells in hand, we generated $W R N I P 1^{-1-1-} / R A D 18^{-1-}$ DT40 cells lines by sequentially transfecting two $R A D 18$ targeting vectors into $W R N I P 1^{-1-1-}$ cells. Disruption of both $R A D 18$ alleles was confirmed by Southern blotting (data not shown) and by RT-PCR (Fig. 1A). A truncated WRNIP1 mRNA was expressed in $W R N I P 1^{-1-1-}$ and $W R N I P 1^{-/-1-} / R A D 18^{-/-}$cells, and the putative truncated WRNIP1 protein appeared to have no biological activity in vivo, based on our previous characterization. ${ }^{15)} \mathrm{Al}$ though the wrnipl (mgsl) rad18 double mutation in budding yeast confers synthetic lethality, WRNIP1 $1^{-1-1-} / R A D 18^{-1-}$ DT40 cells were viable and grew slightly more slowly than either single mutant (Fig. 1B). We did not detect apparent differences among $W R N I P 1^{-1-1-} / R A D 18^{-1-}, R A D 18^{-/-}$, or $W R N I P 1^{-1-1-}$ cells with respect to cell cycle distribution and spontaneous cell death, as monitored by flow cytometry (data not shown).

Additive Increase of Spontaneous SCE in WRNIP1 $^{-1-/-} / \boldsymbol{R A D} 1 \boldsymbol{8}^{-/-}$Cells Increases in mitotic recombination frequency are suggested to be the signal of replication defects. Sister chromatid exchange (SCE) (Fig. 2A) in vertebrate cells is thought to be an excellent indicator of such defects. ${ }^{27)}$ The frequency of SCE in WRNIP $1^{-/-1-} / R A D 18^{-1-}$ cells was increased compared to that of either single mutant (Fig. 2B). As reported previously, ${ }^{25)} R A D 18^{-1-}$ cells exhibited an elevation in SCE (Fig. $2 \mathrm{~B}$, panel b). Since SCE arise mainly via homologous recombination, the elevation of spontaneous $\mathrm{SCE}$ in $R A D 18^{-/-}$ 

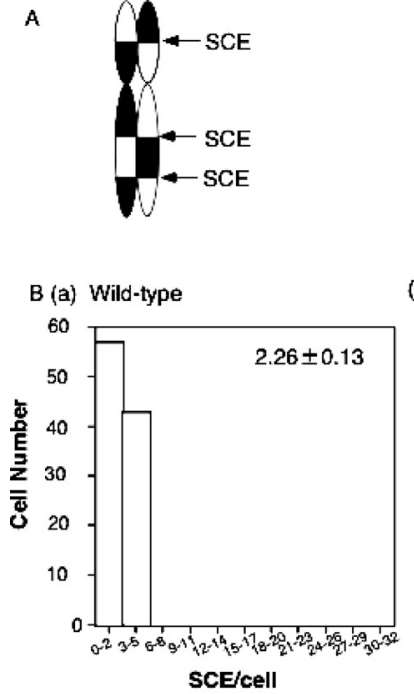

(c) $W R N P^{-/ 4}$

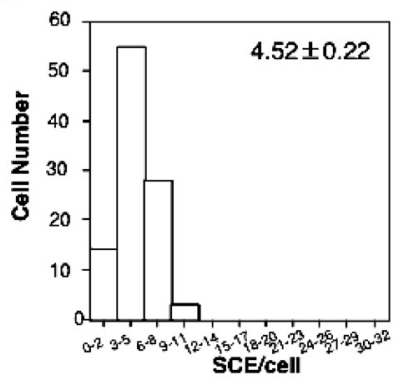

(b) $R A D 18^{\%}$

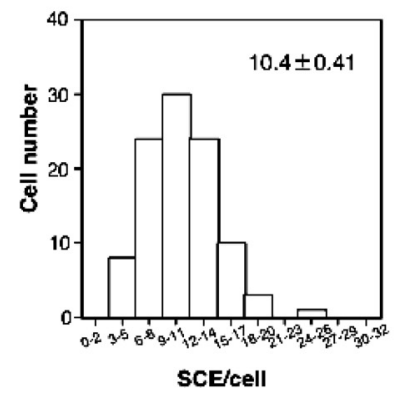

(d) WRNIP-//-/RADI8-

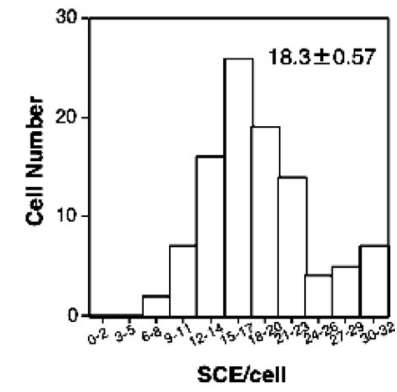

Fig. 2. Frequency of Spontaneous SCE in Various Cells

(A) Schematic presentation of SCE. (B) Histograms of the incidence of SCE in wild-

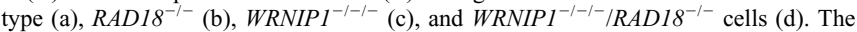
number of SCE in the macro-chromosomes of 100 metaphase cells were counted. Histograms show the number of cells having the indicated number of SCE. The mean and standard error are shown in the upper right corner of each histogram.

cells can be explained by the proposal that lesions that remain on replicating DNA in $R A D 18^{-/-}$cells are channeled to a homologous recombination repair pathway that uses a sister chromatid as a template. ${ }^{25)}$ The frequency of spon-

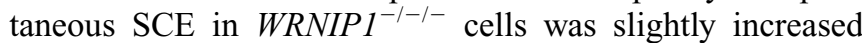
compared with that of wild-type cells (Fig. 2B, panel c) as previously described. ${ }^{15)}$ It is therefore likely that the additive or synergistic increase of spontaneous SCE in WRNIP1 $1^{-1-1-} / R A D 18^{-/-}$cells (Fig. 2B, panel d) indicates a further impairment of DNA replication in cells simultaneously lacking WRNIP1 and Rad18 functions, producing lesions that are processed by homologous recombination. Interestingly, the synthetic lethality of the wrnipl (mgsl) rad18 double mutant of budding yeast is suppressed by enhancing homologous recombination. ${ }^{12)}$ One possible explanation for the viability of $W R N I P 1^{-1-1-} / R A D I 8^{-1-}$ cells is that a homologous recombination pathway is constitutively active in higher eukaryotic cells for responding to replication mishaps that occur in the absence of Rad18 and WRNIP1. Indeed, DT40 RAD $18^{-/-}$cells are reportedly inviable in the absence of Rad54, which is an essential component of homologous recombination ${ }^{25)}$ suggesting that the Rad18 functional defect is mainly compensated for by the Rad54-dependent pathway but not by the WRNIP1 pathway in higher eukaryotic cells.

CPT Sensitivity of WRNIP1 $1^{-l-l-} / R_{A D} 18^{-/-}$Cells $W R N I P 1^{-1-1-}$ cells are not more sensitive to cisplatin

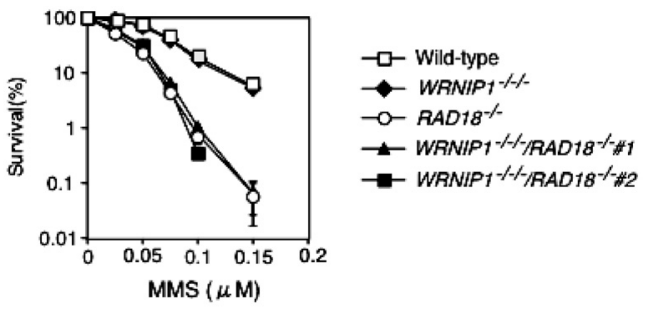

B

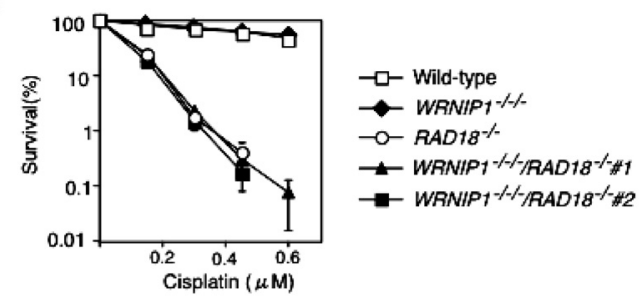

C

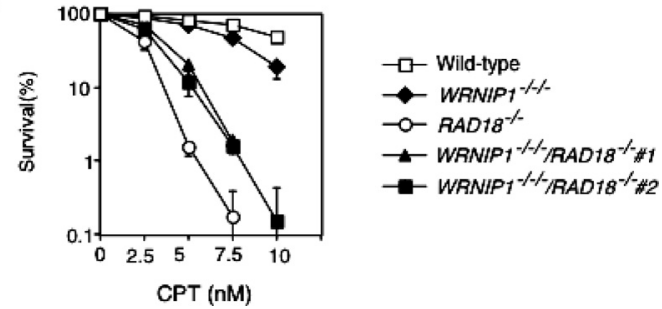

Fig. 3. Sensitivity of $R A D 18^{-/-}, W R N I P 1^{-/-1-}$ and $W R N I P 1^{-1-/-}$ / $R A D 18^{-/-}$DT40 Cells to MMS, CDDP and CPT

Cells were treated with the indicated concentrations of MMS (A), CDDP (B), or CPT (C) as described in Materials and Methods. Survival is expressed as a percentage of the number of colonies that grow in the absence of the indicated genotoxin. The bars represent standard deviations based on data from three independent experiments.

(CDDP) or MMS than wild type cells and they show moderate sensitivity to CPT. ${ }^{15)}$ In contrast, $R A D 18^{-/-}$cells are severely sensitive to all of these drugs, as previously reported (Fig. 3) ${ }^{15,25,26)}$ Here we examined the sensitivity of WRNIP1 $1^{-1-1-} / R A D 18^{-1-}$ cells to MMS, CDDP, and CPT. These cells were as sensitive to MMS and CDDP as $R A D 18^{-/-}$cells, suggesting that WRNIP1 has no role in repairing or tolerating lesions generated by MMS or CDDP, even in the absence of Rad18 (Figs. 3A, B). Surprisingly, the severe CPT sensitivity of $R A D 18^{-1-}$ cells was slightly suppressed by disruption of the WRNIPI gene (Fig. 3C).

CPT is an inhibitor of DNA topoisomerase I (Top1), which forms a complex with DNA. A Top1-mediated transient DNA single-strand break is formed by reversible transfer of a phosphodiester bond to a tyrosine residue in the catalytic site of the enzyme to form a covalently linked Top1-DNA cleavage complex. ${ }^{28-32)}$ CPT associates with Top1 and stabilizes cleavage complexes, which may result in DNA double-strand breaks (DSBs) followed by the ATR/ATM-dependent phosphorylation of $\mathrm{H} 2 \mathrm{AX}$ when DNA replication forks encounter these lesions. ${ }^{33,34)}$ It has been shown that DSBs induced by CPT are mainly repaired by homologous recombination in DT40 cells. ${ }^{35)}$

Defect in the Induction of SCE by CPT in RAD18 and WRNIP1 $^{-1-1-} / \boldsymbol{R} A D 18^{-1-}$ Cells How does impairment of the WRNIP1 function slightly suppress the severe CPT sensitivity of $R A D 18^{-/-}$cells? Since overproduction of a protein involved in homologous recombination rescues the 


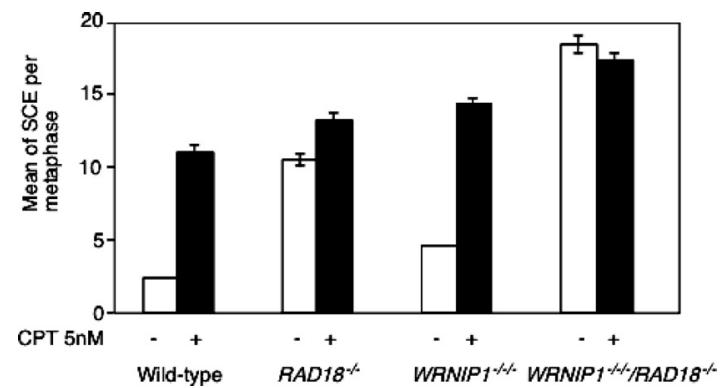

Fig. 4. Induction of SCE by CPT in Various Cells

The numbers of SCEs in the macro-chromosomes of 100 metaphase cells were counted. Cells were treated with $5 \mathrm{~nm}$ CPT for $8 \mathrm{~h}$ (filled column) or not treated (open column). Columns and bars represent means and standard errors.

lethality of wrnipl (mgsl) rad18 cells in budding yeast, ${ }^{12)}$ we examined the induction of SCE in various cells upon exposure to CPT.

In the presence of CPT, SCE frequencis in wild-type cells and $W R N I P 1^{-1-1-}$ cells were higher than those of spontaneous SCE by about 5-fold and 3-fold, respectively, while only 1.3-fold increase in SCE frequency was observed in $R A D 18^{-1-}$ cells. In the case of WRNIP1 $1^{-1-1-} / R A D 18^{-1-}$ cells, no induction of SCE by CPT occurred although the frequencies of spontaneous and CPT-induced SCE in the cells were higher than those of either $R A D 18^{-/-}$or $W R N I P 1^{-/-1-}$ cells (Fig. 4). These data indicate that the induction of SCE by CPT is as proficient in WRNIP $1^{-1-1-}$ cells like as in wild type cells but that it is defective in both $R A D 18^{-1-}$ and $W R N I P 1^{-/-1-} / R A D 18^{-/-}$cells. Thus, it is unlikely that the partial suppression of the CPT sensitivity of $R A D 18^{-1-}$ cells by disruption of the WRNIP1 gene is due to the induction of recombination.

In conclusion, WRNIP1 and Rad18 in higher eukaryotic cells deal with DNA lesions encountered by replication forks in different pathways, and the lesions that persist in the absence of these proteins are processed by homologous recombination. Thus, both WRNIP1 and Rad18 suppress spontaneously occurring SCE. However, when replication forks encounter lesions induced by CPT, Rad 18 processes lesions in a pathway that results in homologous recombination. The behavior of Rad18 is not surprising because Sgs1, the yeast homolog of RecQ, suppresses spontaneous homologous recombination, and it is required for homologous recombination induced by DNA damaging agents such as MMS. ${ }^{36)}$ In addition, a pathway involving both WRNIP1 and Rad18, in which WRNIP1 functions upstream of Rad18, operates in the presence of CPT. In the absence of WRNIP1, the lesions processed by this pathway are channeled to other pathways, thereby partially suppressing the CPT sensitivity of WRNIP $1^{-/-1-} / R A D 18^{-/-}$cells as compared with $R A D 18^{-/-}$ cells. The elucidation of this pathway is one of our future goals. Recently, it has been reported that yeast Mgs1 (yWRNIP1) interacts with PCNA, which is essential for polymerase $\delta$ to replicate DNA processively. ${ }^{37)}$ Interestingly, both human WRNIP1 and yeast Mgs1 interact with DNA polymerase $\delta .^{14,38)}$ Taking into account that Rad18 is required for the modification of PCNA with ubiquitin, some interplays among Rad18, WRNIP1, PCNA, and DNA polymease $\delta$, seem to operate to deal with CPT-induced DNA lesions. Thus, simultaneous deletion of WRNIP1 and Rad18 affects such interplays and then activates other pathway to deal with CPT lesions. Finally, the functional interaction of Rad18 and WRNIP1 is dynamic, and it changes depending on the type of lesion and situation of cells.

Acknowledgements This work was supported by Grants-in-Aid for Scientific Research and for Scientific Research on Priority Areas from the Ministry of Education, Culture, Sports, Science and Technology of Japan.

\section{REFERENCES}

1) Epstein C. J., Martin G. M., Schultz A. L., Motulsky A. G., Medicine (Baltimore), 45, 177-221 (1966).

2) Yu C. E., Oshima J., Fu Y. H., Wijsman E. M., Hisama F., Alisch R., Matthews S., Nakura J., Miki T., Martin G. M., Mulligan J., Schellenberg G. D., Science, 272, 258-262 (1996).

3) Suzuki N., Shimamoto A., Imamura O., Kuromitsu J., Kitao S., Goto M., Furuichi Y., Nucleic Acids Res., 25, 2973-2978 (1997).

4) Gray M. D., Shen J. C., Kamath-Loeb A. S., Blank A., Sopher B. L., Martin G. M., Oshima J., Loeb L. A., Nat. Genet., 17, 100-103 (1997).

5) Huang S., Li B., Gray M. D., Oshima J., Mian I. S., Campisi J., Nat Genet., 20, 114-116 (1998).

6) Suzuki N., Shiratori M., Goto M., Furuichi Y., Nucleic Acids Res., 27, 2361-2368 (1999).

7) Crabbe L., Verdun R. E., Haggblom C. I., Karlseder J., Science, 306, 1951-1953 (2004).

8) Du X., Shen J., Kugan N., Furth E. E., Lombard D. B., Cheung C., Pak S., Luo G., Pignolo R. J., DePinho R. A., Guarente L., Johnson F. B., Mol. Cell Biol., 24, 8437-8446 (2004).

9) Kamath-Loeb A. S., Johansson E., Burgers P. M., Loeb L. A., Proc. Natl. Acad. Sci. U.S.A., 97, 4603-4608 (2000).

10) Kawabe Y., Branzei D., Hayashi T., Suzuki H., Masuko T., Onoda F., Heo S. J., Ikeda H., Shimamoto A., Furuichi Y., Seki M., Enomoto T., J. Biol. Chem., 276, 20364-20369 (2001).

11) Hishida T., Iwasaki H., Ohno T., Morishita T., Shinagawa H., Proc Natl. Acad. Sci. U.S.A., 98, 8283-8289 (2001).

12) Hishida T., Ohno T., Iwasaki H., Shinagawa H., EMBO J., 21, 2019 2029 (2002).

13) Branzei D., Seki M., Onoda F., Enomoto T., Mol. Genet. Genomics, 268, 371-386 (2002).

14) Tsurimoto T., Shinozaki A., Yano M., Seki M., Enomoto T., Genes Cells, 10, 13-22 (2005).

15) Kawabe Y., Seki M., Yoshimura A., Nishino K., Hayashi T., Takeuchi T., Iguchi S., Kusa Y., Ohtsuki M., Tsuyama T., Imamura O., Matsumoto T., Furuichi Y., Tada S., Enomoto T., DNA Repair, 5, 816-828 (2006).

16) Ulrich H. D., Jentsch S., EMBO J., 19, 3388-3399 (2000).

17) Hoege C., Pfander B., Moldovan G. L., Pyrovolakis G., Jentsch S., Nature (London), 419, 135-141 (2002).

18) Haracska L., Torres-Ramos C. A., Johnson R. E., Parakash S., Prakash L., Mol. Cell Biol., 24, 4267-4274 (2004).

19) Broomfield S., Hryciw T., Xiao W., Mutat. Res., 486, 167-184 (2001).

20) Haracska L., Kondratick C. M., Unk I., Parakash S., Prakash L., Mol. Cell, 8, 407-415 (2001).

21) Lawrence C. W., Chrintensen R., Genetics, 82, 207-232 (1976).

22) Prakash L., Mol. Gen. Genet., 184, 471-478 (1981).

23) Tomita H., Soshi T., Inoue H., Mol. Gen. Genet., 238, 225-233 (1993).

24) Tateishi S., Niwa H., Miyazaki J., Fujimoto S., Inoue H., Yamaizumi M., Mol. Cell Biol., 23, $474-481$ (2003).

25) Yamashita Y. M., Okada T., Matsusaka T., Sonoda E., Zhao G. Y., Araki K., Tateishi S., Yamaizumi M., Takeda S., EMBO J., 20, 5558 5566 (2002).

26) Yoshimura A., Nishino K., Takezawa J., Tada S., Kobayashi T., Sonoda E., Kawamoto T., Takeda S., Ishii Y., Yamada K., Enomoto T., Seki M., DNA Repair in press.

27) Sonoda E., Sasaki M. S., Morrison C., Yamaguchi-Iwai Y., Takata M., Takeda S., Mol. Cell Biol., 19, 5166-5169 (1999). 
28) Liu L. F., Annu. Rev. Biochem., 58, 351-375 (1989).

29) Wang J. C., Annu. Rev. Biochem., 65, 635-692 (1996).

30) Champoux J. J., Ann. N.Y. Acad. Sci., 922, 56-64 (2000).

31) Hsiang Y. H., Hertzberg R., Hecht S., Liu L. F., J. Biol. Chem., 260, $14873-14878$ (1985).

32) Hsiang Y. H., Lihou M. G., Liu L. F., Cancer Res., 49, 5077-5082 (1989).

33) Huang X., Traganos F., Darzynkiewicz Z., Cell Cycle, 2, 614-619 (2003).

34) Furuta T., Takemura H., Liao Z. Y., Aune G. J., Redon C., Sedelnikova O. A., Pilch D. R., Rogakou E. P., Celeste A., Chen H. T., Nussenzweig
A., Aladjem M. I., Bonner W. M., Pommier Y., J. Biol. Chem., 278, 20303-20312 (2003).

35) Adachi N., So S., Koyama H., J. Biol. Chem., 279, 37343-37348 (2004).

36) Onoda F., Seki M., Miyajima A., Enomoto T., Mol. Gen. Genet., 264, $702-708$ (2001)

37) Hishida T., Ohya T., Kubota Y., Kamada Y., Shinagawa H., Mol. Cell Biol., 26, 5509-5517 (2006).

38) Davoodi Vijeh Motlagh N., Seki M., Branzei D., Enomoto T., DNA Repair, in press. 